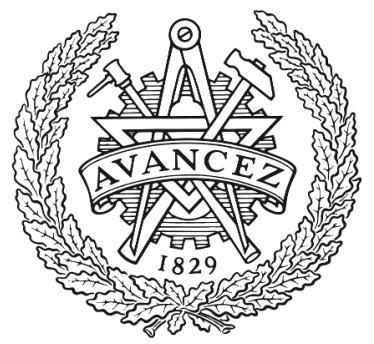

CHALMERS

UNIVERSITY OF TECHNOLOGY

\title{
Recyclable Polyethylene Insulation via Reactive Compounding with a Maleic Anhydride-Grafted Polypropylene
}

Downloaded from: https://research.chalmers.se, 2023-04-26 10:27 UTC

Citation for the original published paper (version of record):

Ouyang, Y., Mauri, M., Pourrahimi, A. et al (2020). Recyclable Polyethylene Insulation via Reactive Compounding with a Maleic Anhydride-Grafted

Polypropylene. ACS Applied Polymer Materials, 2(6): 2389-2396.

http://dx.doi.org/10.1021/acsapm.0c00320

N.B. When citing this work, cite the original published paper. 


\title{
Recyclable Polyethylene Insulation via Reactive Compounding with a Maleic Anhydride-Grafted Polypropylene
}

\author{
Yingwei Ouyang, Massimiliano Mauri, Amir Masoud Pourrahimi, Ida Östergren, Anja Lund, \\ Thomas Gkourmpis, Oscar Prieto, Xiangdong Xu, Per-Ola Hagstrand, and Christian Müller*
}

Cite This: ACS Appl. Polym. Mater. 2020, 2, 2389-2396

Read Online

ACCESS | Lill Metrics \& More | 国 Article Recommendations ｜ st Supporting Information

ABSTRACT: The most common type of extruded power cable insulation is based on crosslinked polyethylene (XLPE), which cannot be recycled as a thermoplastic material. Hence, thermoplastic insulation materials currently receive considerable attention because they would allow recycling through re-melting. In particular blends of polyethylene (PE) and polypropylene (PP) would be a compelling alternative to XLPE, provided that the poor compatibility of the two polymers can be overcome. Here, we establish an alternative approach that exploits the in situ formation of a PE-PP-type copolymer through reactive compounding. Ternary blends of an ethylene-glycidyl methacrylate copolymer, a maleic anhydride-grafted polypropylene, and up to $70 \mathrm{wt} \%$ low-density polyethylene (LDPE) are compounded at 170 ${ }^{\circ} \mathrm{C}$. Covalent bonds form through reaction between epoxy and carboxyl groups, leading to a PE-PP-type copolymer that shows good compatibility with LDPE. The in situ generated PEPP copolymer arrests creep above the melting temperature of LDPE, mediated by a continuous network that is held together by PP crystallites. Recyclability is confirmed by reprocessing at $170{ }^{\circ} \mathrm{C}$. Furthermore, the here investigated formulations feature a low directcurrent electrical conductivity of $\sim 4 \times 10^{-14} \mathrm{~S} \mathrm{~m}^{-1}$ at $70{ }^{\circ} \mathrm{C}$ and $30 \mathrm{kV} \mathrm{mm}^{-1}$, on a par with values measured for LDPE and XLPE. Evidently, in situ formation of a PE-PP-type copolymer through reactive compounding is a promising approach that may enable the design of thermoplastic insulation materials for power cables.

KEYWORDS: high-voltage power cable insulation, polypropylene, reactive compounding, thermoplastic, recycling

\section{INTRODUCTION}

Solar, wind, and hydropower are usually most abundant in unpopulated areas that are located far away from the end user, which necessitates the efficient transport of energy over long distances. Furthermore, since renewable sources of energy are intermittent, transmission lines are needed that can reverse the direction of energy flow. High-voltage direct-current (HVDC) transmission lines meet these demands and are therefore an important part of future power grids that seamlessly integrate renewables. ${ }^{1,2}$ When transmission lines transverse large bodies of water or densely populated areas, power cables need to be submerged or buried underground and therefore must be surrounded by an insulation layer. Considerable research efforts are being dedicated to improving the quality of the cable insulation, which may allow the transmission voltage to increase beyond the limit of $640 \mathrm{kV}$ that is possible today. ${ }^{2}$

Currently, the most widely used material for HVDC cable insulation is low-density polyethylene (LDPE). LDPE can be produced with high chemical and physical cleanliness, resulting in a very low $\mathrm{DC}$ electrical conductivity of typically $\sigma_{\mathrm{DC}} \approx$ $10^{-14} \mathrm{~S} \mathrm{~m}^{-1}$ at an electrical field of $30 \mathrm{kV} \mathrm{mm}^{-1}$ and a typical cable operating temperature of $70{ }^{\circ} \mathrm{C} .{ }^{3}$ One disadvantage of LDPE is its low melting temperature of $T_{\mathrm{m}} \approx 110{ }^{\circ} \mathrm{C}$, which limits the temperature that the insulation material can withstand. The most common solution is to cross-link LDPE, typically with a peroxide such as dicumyl peroxide (DCP), to form cross-linked polyethylene (XLPE). The curing reaction produces volatile and hazardous byproducts such as water, methane, acetophenone, cumyl alcohol, and $\alpha$ methylstyrene, ${ }^{4,5}$ which must be removed through a timeand energy-consuming degassing procedure. ${ }^{6}$ The overall quality of an insulation material is negatively affected by any remaining impurities, $^{7-9}$ and therefore, strategies that avoid the use of peroxide cross-linking, such as click chemistry-based curing $^{10-13}$ or the use of hydrogen bonding motifs, ${ }^{14,15}$ are in high demand.

An intriguing alternative to cross-linking is the addition of a higher-melting polymer whose crystals remain intact above the $T_{\mathrm{m}}$ of LDPE. The resulting thermoplastic polymer blend may allow the design of cross-linking-free insulation materials that are easier to recycle once the cable has reached the end of its

Received: March 27, 2020

Accepted: May 8, 2020

Published: May 21, 2020 
lifetime. A rubber-like plateau modulus will occur within a temperature window between the respective $T_{\mathrm{m}}$ of each polymer, provided that the higher-melting crystals are part of a continuous network. One example that illustrates this principle is blending of LDPE with high-density polyethylene (HDPE). ${ }^{16-18}$ We have shown that a few percent of HDPE with a $T_{\mathrm{m}} \approx 130{ }^{\circ} \mathrm{C}$ are sufficient to form a continuous network of HDPE crystallites connected via tie chains and trapped entanglements. ${ }^{16}$ This network is able to enhance the melt stiffness and creep resistance within a narrow temperature window above the $T_{\mathrm{m}}$ of LDPE. ${ }^{17}$ Furthermore, polyethylene (PE) blends can feature an about one order of magnitude lower conductivity as compared to neat LDPE. ${ }^{3}$

The addition of polypropylene (PP), which can have a $T_{\mathrm{m}}$ as high as $165^{\circ} \mathrm{C}$, may allow significant extension of the rubberlike temperature window above the $T_{\mathrm{m}}$ of LDPE. While isotactic PP alone is not a suitable cable insulation material because it becomes too brittle at low temperatures and is too stiff at $70{ }^{\circ} \mathrm{C}$, its combination with PE receives considerable attention. In particular PE-PP copolymers are widely explored because they can overcome the poor compatibility of blends, leading to materials that combine the high melting temperature of PP with the superior cleanliness and toughness of PE. A number of recent studies investigate the dielectric properties of PE-PP copolymers, ${ }^{19-23}$ and first commercial solutions are now available. ${ }^{24}$ However, many types of PE-PP copolymers remain specialty additives, and hence it would be of interest to develop alternative, cost-effective concepts that allow preparation of materials with similar properties.

Here, we explore the in situ generation of a PE-PP-type copolymer through reactive compounding using materials that are readily available on an industrial scale. In an industrial setting, the reactive compounding step could be carried out prior to the shaping process, i.e., cable extrusion, which would alleviate the need for both cross-linking and degassing steps (Figure 1). We chose to work with a branched statistical ethylene-glycidyl methacrylate copolymer p(E-stat-GMA), which is widely used as a reactive compatibilizer for polymer blends ${ }^{25-28}$ and is of promise for byproduct-free cross-linking of PE-based materials. ${ }^{10-13,29}$ As the PP material, we selected a maleic anhydride-grafted polypropylene (PP-graft-MA), which is a common coupling agent, interface modifier, and compatibilizer for PP-based blends and composites ${ }^{30,31}$ and displays excellent dielectric properties. ${ }^{21,32}$ During compounding of the two copolymers and LDPE, covalent links form that connect $\mathrm{p}$ (E-stat-GMA) and (PP-graft-MA) through reaction between epoxy and carboxyl functional groups. The resulting branched PE-PP-type copolymer shows good compatibility with LDPE and hence considerably enhances the melt creep resistance of LDPE. At the same time, the electrical DC conductivity is not affected by the presence of the various functional groups, in agreement with our recent work on $\mathrm{p}(\mathrm{E}$ stat-GMA)-based thermosets, ${ }^{12,13}$ which opens up a new avenue for the preparation of creep-resistant yet thermoplastic insulation materials.

\section{RESULTS AND DISCUSSION}

In the first set of experiments, we studied the reactivity of $\mathrm{p}$ (Estat-GMA) and PP-graft-MA, which we mixed at a ratio of $4: 1$ by weight (see Figure 2 for chemical structures), corresponding to a 1:1 molar ratio of epoxy and carboxyl functional groups in the two polymers (note that each succinic anhydride yields two carboxyl groups). Anhydrides do not react with

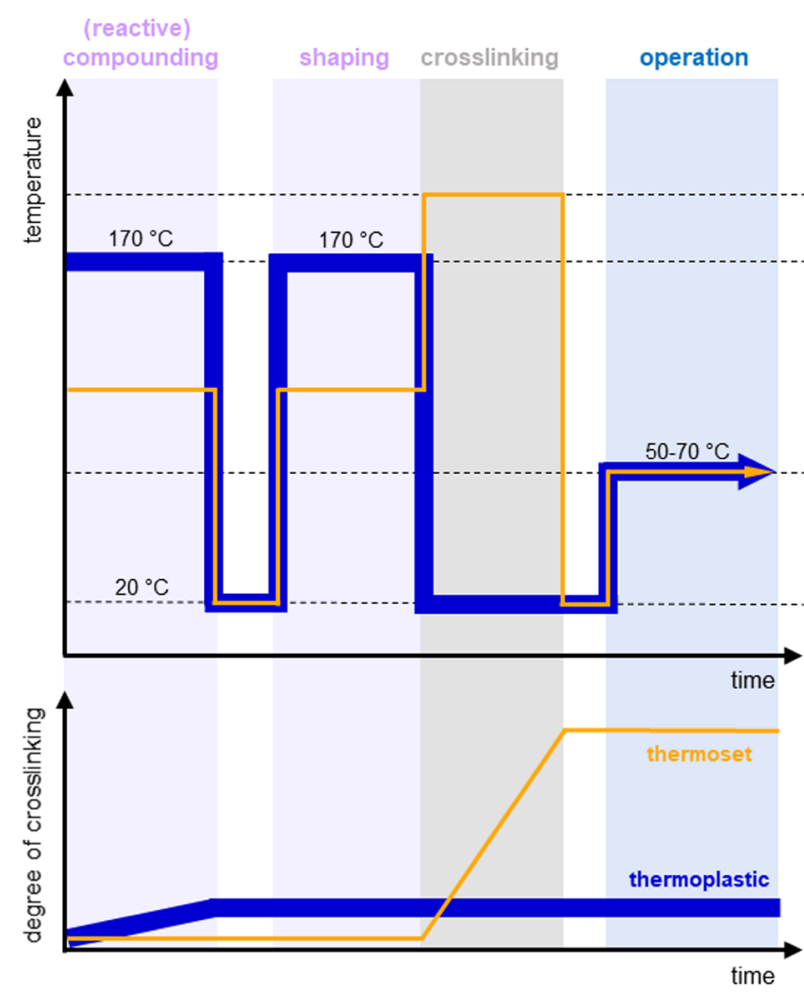

Figure 1. Schematic of the experienced temperature and degree of cross-linking of a traditional thermoset cable insulation material (orange line) and a thermoplastic insulation material prepared by reactive compounding (blue line) during compounding and shaping (purple), the heat activated cross-linking step (gray), which is absent for the thermoplastic material, and operation (blue).

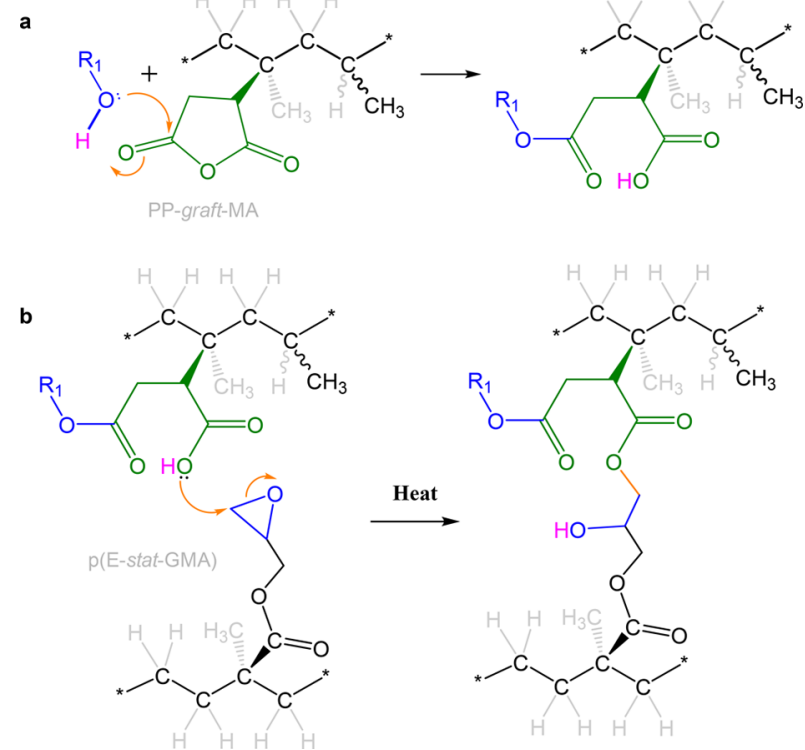

Figure 2. (a) Activation of PP-graft-MA by ring opening through reaction with water $\left(\mathrm{R}_{1}=\mathrm{H}\right)$ leading to two carboxyl groups. (b) Activated succinic anhydride reacting with an epoxy group, part of the GMA comonomer of $\mathrm{p}$ (E-stat-GMA). The second functional group carries a generic $R_{1}$ group because ring opening can occur not only by reaction with water but also by reaction with another carboxyl or a hydroxyl group that was formed through an epoxy opening reaction.

epoxy groups directly, so the succinic anhydride rings of PPgraft-MA need to be opened before the $\mathrm{p}$ (E-stat-GMA) and 
PP-graft-MA can react with each other. Carboxyl groups in the ring-opened PP-graft-MA then react with the oxirane ring that is part of the $\mathrm{p}$ (E-stat-GMA), leading to the formation of a new hydroxyl group and an ester that covalently links the $\mathrm{p}$ (E-statGMA) and PP-graft-MA to generate a PE-PP-type copolymer without releasing any byproducts. Since our PP-graft-MA was exposed to ambient conditions prior to compounding, the uptake of water results in opening of succinic anhydride rings, which leads to the formation of two carboxyl groups (see Figure 2). FTIR spectroscopy of neat PP-graft-MA revealed the presence of two distinct carbonyl stretch vibrations at 1781 and $1718 \mathrm{~cm}^{-1}$, which we assign to the anhydride and acid form, respectively (Figure 3a). ${ }^{33}$ At $40{ }^{\circ} \mathrm{C}$, we observe a sizeable $1718 \mathrm{~cm}^{-1}$ acid peak, suggesting that prior to compounding, a substantial amount of the succinic anhydride rings would have been opened by water. Variable-temperature FTIR spectroscopy allowed us to follow the change in absorbance intensities of the carbonyl peaks of the anhydride and acid as a function of temperature (Figure $3 \mathrm{~b}$ ). Upon heating, the carbonyl stretch vibration at $1718 \mathrm{~cm}^{-1}$, which is characteristic of the carboxylic acid, gradually diminishes, indicating recovery of the closed succinic anhydride ring. We find that at $170{ }^{\circ} \mathrm{C}$, which lies above the melting temperature of PP-graft-MA $\left(T_{\mathrm{m}} \approx 155{ }^{\circ} \mathrm{C}\right.$, Table 1$)$, a small fraction of carboxyl groups remains. Therefore, we chose to process our materials at $170{ }^{\circ} \mathrm{C}$ since at this temperature, both copolymers are molten and the envisaged reaction between epoxy and carboxyl groups can still take place.

FTIR spectroscopy allowed us to confirm that the reaction between epoxy and carboxyl groups occurs. Binary blends of $\mathrm{p}$ (E-stat-GMA) and PP-graft-MA display three distinct carbonyl stretch vibrations, which correspond to succinic anhydride $\left(1781 \mathrm{~cm}^{-1}\right)$, carboxylic acid $\left(1718 \mathrm{~cm}^{-1}\right)$, and an intermediate peak from the ester of GMA $\left(1735 \mathrm{~cm}^{-1}\right.$ ) (Figure $3 c)$. The intensity of the carboxyl signal strongly increases after annealing for $20 \mathrm{~min}$ at $170{ }^{\circ} \mathrm{C}$, while the anhydride signal decreases in intensity, which we rationalize with a reaction between epoxy and carboxyl groups. The closed and open forms of succinic anhydride (plus water) and acid are present in a chemical equilibrium, meaning that each succinic anhydride will open up occasionally. Since the reaction of epoxy and carboxyl groups readily proceeds at $170{ }^{\circ} \mathrm{C},{ }^{12,13}$ also the succinic anhydride is gradually consumed because once one of two carboxylic acid groups has reacted, the second one cannot revert back to the closed anhydride form. Furthermore, consumption of epoxy groups is confirmed by inspection of the characteristic signal at $911 \mathrm{~cm}^{-1}$, which is associated with $\mathrm{C}-\mathrm{O}$ deformation of the oxirane ring. A binary blend compounded for $5 \mathrm{~min}$ at $170{ }^{\circ} \mathrm{C}$ shows a reduction in peak height by $33 \%$ as compared to neat $\mathrm{p}$ (E-stat-GMA) (Figure $\mathrm{S} 1$ ), which suggests that about one in three epoxy groups has reacted.

It can be anticipated that the cross-linking reaction between the two copolymers proceeds as long as the binary blend is cured at elevated temperatures. During a continuous manufacturing process scorch may occur, i.e., the gradual buildup of the excessively cured material that experiences long dwell times within stagnant sections of an extruder. Neat $\mathrm{p}(\mathrm{E}$ stat-GMA) has a shear storage modulus of $G^{\prime} \approx 1.2 \times 10^{4} \mathrm{~Pa}$ at $170{ }^{\circ} \mathrm{C}$ (Figure S2b). We argue that the unreacted binary blend would display a similar modulus (note that PP-graft-MA has a low molecular weight; cf. Experimental Section). The freshly compounded binary blend has a modulus of $G^{\prime} \approx 5 \times$ $10^{4} \mathrm{~Pa}$ at $170{ }^{\circ} \mathrm{C}$, which confirms that some of the epoxy and
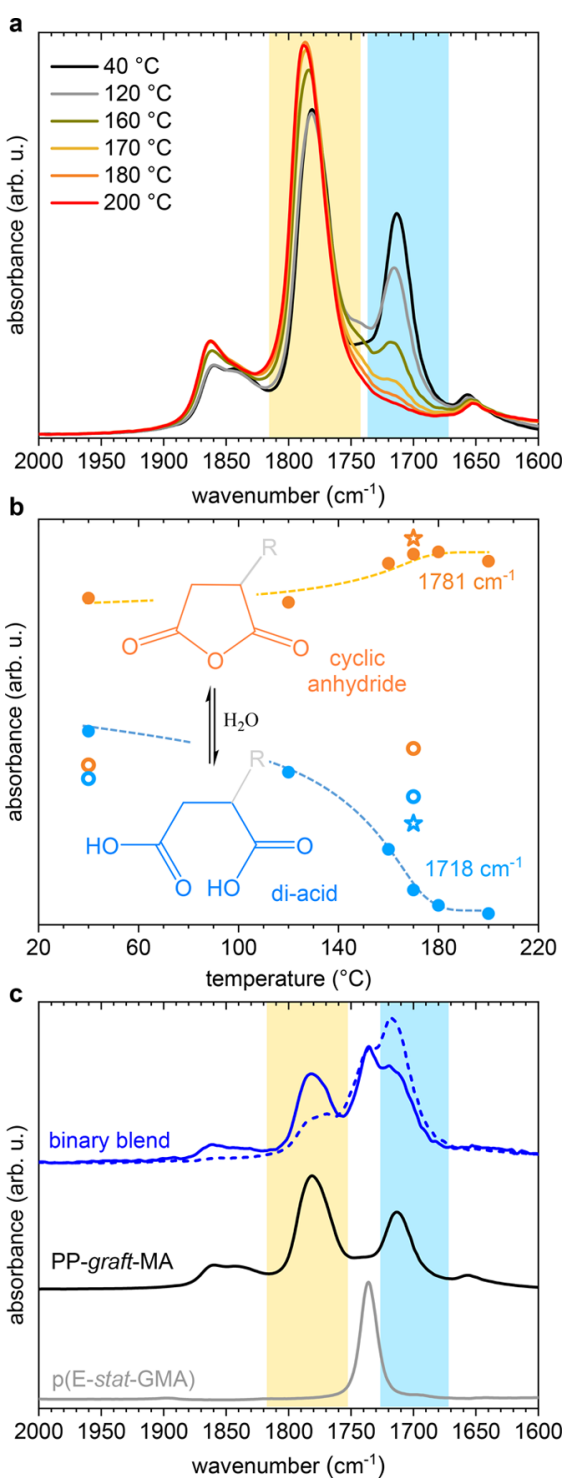

Figure 3. (a) FTIR spectra of PP-graft-MA at increasing temperatures from 40 to $220{ }^{\circ} \mathrm{C}$. (b) Absorbance intensity at $1718 \mathrm{~cm}^{-1}$ for the acid (blue) and $1781 \mathrm{~cm}^{-1}$ for the anhydride (orange) plotted against temperature for PP-graft-MA (filled circles), the binary blend (hollow circles), and the binary blend after $20 \mathrm{~min}$ at $170{ }^{\circ} \mathrm{C}$ (hollow star) (inset: reaction scheme of the reversible conversion between the cyclic anhydride and opened di-acid forms of the succinic anhydride grafted onto polypropylene, where $\mathrm{R}=$ polypropylene chain). (c) FTIR spectra measured near room temperature of $p$ (E-stat-GMA) (gray, solid), PP-graft-MA (black, solid), the binary blend compounded for $5 \mathrm{~min}$ at $170{ }^{\circ} \mathrm{C}$ (blue, solid) and the same binary material after annealing at $170{ }^{\circ} \mathrm{C}$ for $20 \mathrm{~min}$ (blue, dashed).

carboxyl groups have reacted during the 5 min compounding step. Oscillatory shear rheometry allowed us to monitor $G^{\prime}$ of the binary blend during continuous curing (Figure 4). We find that $G^{\prime}$ gradually increases to $9.5 \times 10^{4} \mathrm{~Pa}$ after curing for a total of $40 \mathrm{~min}$, which indicates that the curing reaction continues to proceed, albeit slowly. Neat $p$ (E-stat-GMA) displays no significant change in modulus during curing (Figure S2), which confirms that we can ascribe the change in $G^{\prime}$ to the reaction between epoxy and carboxyl groups and not any degradation reaction or epoxy homopolymerization.

To reduce the speed of the curing reaction, we decided to dilute the binary blend with 70 wt \% neat LDPE. We 
Table 1. Peak Melting Temperatures of the PE and PP Phase $\left(T_{\mathrm{m}}^{\mathrm{PE}}\right.$ and $\left.T_{\mathrm{m}}^{\mathrm{PP}}\right)$, Enthalpy of Fusion relative to the PE and PP Content $\left(\Delta H_{\mathrm{m}}^{\mathrm{PE}}\right.$ and $\left.\Delta H_{\mathrm{m}}^{\mathrm{PP}}\right)$, Gel Content of Pressed Samples, Creep Strain after $100 \mathrm{~min}$ at $120{ }^{\circ} \mathrm{C}$ and a Stress of $1 \mathrm{kPa}$ $\left(\varepsilon_{\text {creep }}^{120^{\circ} \mathrm{C}}\right)$, and Direct-Current Electrical Conductivity at an Electrical Field of $30 \mathrm{kV} \mathrm{mm} \mathrm{m}^{-1}$ after $18 \mathrm{~h}\left(\sigma_{\mathrm{DC}}\right)$ of the Neat Polymers Used in This Study as well as the Binary Blend 4:1 p(E-stat-GMA):PP-graft-MA and the Ternary Blend 24:6:70 p(E-statGMA):PP-graft-MA:LDPE Compounded at $170{ }^{\circ} \mathrm{C}^{a}$

\begin{tabular}{|c|c|c|c|c|c|c|c|}
\hline compound & $T_{\mathrm{m}}^{\mathrm{PE}}\left({ }^{\circ} \mathrm{C}\right)$ & $T_{\mathrm{m}}^{\mathrm{PP}}\left({ }^{\circ} \mathrm{C}\right)$ & $\Delta H_{\mathrm{m}}^{\mathrm{PE}}\left(\mathrm{J} \mathrm{g}^{-1}\right)$ & $\Delta H_{\mathrm{m}}^{\mathrm{PP}}\left(\mathrm{J} \mathrm{g}^{-1}\right)$ & gel content (\%) & $\varepsilon_{\text {creep }}^{120^{\circ} \mathrm{C}}(\%)$ & $\sigma_{\mathrm{DC}}$ at $70{ }^{\circ} \mathrm{C}\left(10^{-14} \mathrm{~S} \mathrm{~m}^{-1}\right)$ \\
\hline $\mathrm{p}(\mathrm{E}-$ stat-GMA $)$ & 110 & & 105 & & & fail & n.m. \\
\hline PP-graft-MA & & 155 & & 65 & & n.m. & n.m. \\
\hline LDPE & 111 & & 126 & & & fail & $2.5( \pm 0.3)$ \\
\hline XLPE & 108 & & 96 & & 72 & 0.2 & $4.0( \pm 0.4)$ \\
\hline binary blend & 108 & 155 & 93 & 48 & 66 & n.m. & n.m. \\
\hline ternary blend & 111 & 163 & 103 & 5 & 32 & 12 & $4.4( \pm 0.4)$ \\
\hline
\end{tabular}

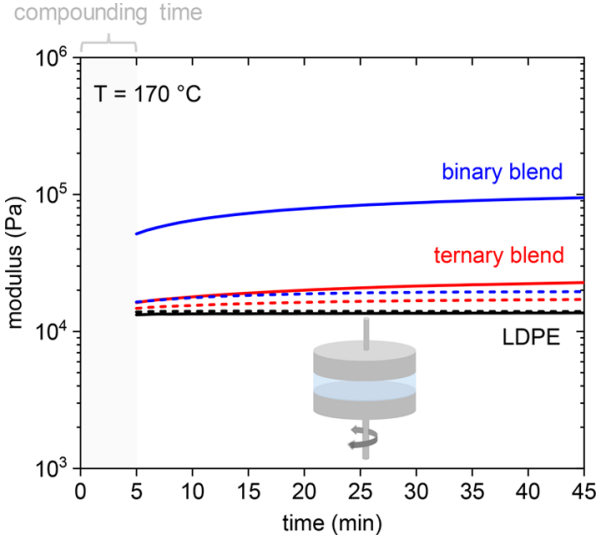

Figure 4. Shear storage and loss modulus $\left(G^{\prime}\right.$ and $G^{\prime \prime}$, solid and dashed, respectively), measured with oscillatory shear rheometry at $170{ }^{\circ} \mathrm{C}$, of the $4: 1 \mathrm{p}($ E-stat-GMA):PP-graft-MA binary blend (blue) and the 24:6:70 $\mathrm{p}(\mathrm{E}$-stat-GMA):PP-graft-MA:LDPE ternary blend (red), both compounded at $170{ }^{\circ} \mathrm{C}$ for $5 \mathrm{~min}$ and pressed at $170{ }^{\circ} \mathrm{C}$ for $1 \mathrm{~min}$, and neat LDPE (black) (inset: schematic of the oscillatory shear rheometry measurement).

compounded a ternary blend with a composition of 24:6:70 $\mathrm{p}$ (E-stat-GMA):PP-graft-MA:LDPE by weight $(\sim 1: 2$ GMA:MA molar ratio). The freshly compounded ternary blend displays a shear modulus of $G^{\prime} \approx 1.6 \times 10^{4} \mathrm{~Pa}$ at $170^{\circ} \mathrm{C}$, which is only slightly higher than the modulus of neat LDPE (Figure 4). Oscillatory shear rheometry during continuous curing indicates that the increase in $G^{\prime}$ and hence the reaction between epoxy and carboxyl groups proceeds more gradually as compared to the binary blend. As a result, the ternary blend and LDPE feature a similar complex viscosity of 3.5 and $3 \mathrm{kPa}$. $\mathrm{s}$, respectively, meaning that curing of the two copolymers does not strongly affect the melt flow properties of the resin.

Curing of $\mathrm{p}$ (E-stat-GMA) and PP-graft-MA results in the formation of a PE-PP-type copolymer. Scanning electron microscopy (SEM) images of the fracture surfaces of cryofractured samples indicate that no strong phase separation occurs in the blends studied here. While a reference blend of (isotactic) PP and LDPE with the same weight ratio as our binary blend featured distinct micrometer-sized polypropylene domains, we observe a considerably more fine-grained microstructure for our binary and ternary blends (Figure S3).

To investigate how the curing of $\mathrm{p}$ (E-stat-GMA) and PPgraft-MA affects the thermomechanical properties of our blends, we first employed dynamic mechanical analysis (DMA) in tensile mode, with a maximum strain set to $1 \%$, to assess the degree of reinforcement provided by the PP crystallites above the melting temperature of polyethylene. Reference XLPE, which had a gel content of $72 \%$, showed a clear rubber plateau at $E^{\prime} \approx 395 \mathrm{kPa}$ at $140{ }^{\circ} \mathrm{C}$. We calculated the network density from the molecular weight between cross-links $M_{\mathrm{c}}$ according to

$$
M_{\mathrm{c}}=\frac{\rho R T}{E^{\prime}}
$$

where $\rho$ is the density, $R$ is the universal gas constant, $T$ is the temperature, and $E^{\prime}$ is the value of the plateau modulus ( $\rho=$ $0.789 \mathrm{~g} \mathrm{~cm}^{-3}$ at $140{ }^{\circ} \mathrm{C} ; \rho=0.770 \mathrm{~g} \mathrm{~cm}^{-3}$ at $\left.170{ }^{\circ} \mathrm{C}\right)$. The number of network points per $10^{3}$ carbons $\left(-\mathrm{CH}_{2}-\right)$ was then estimated by dividing $14 \times 10^{3} \mathrm{~g} \mathrm{~mol}^{-1}$ with $M_{\mathrm{c}}$. For XLPE, we calculate a network density of 20 cross-links per $10^{4}$ carbons. The binary and ternary blends contain different types of network points above the melting temperature of polyethylene: (1) entanglements, (2) branching points, (3) covalent crosslinks formed through the reaction between epoxy and carboxyl groups, and (4) physical network points in the form of PP crystallites. We estimated the number of network points that arises due to the presence of PP crystallites by comparing the storage modulus below and above the melting point of polypropylene. For the binary blend, we find $E^{\prime} \approx 360 \mathrm{kPa}$ at $140{ }^{\circ} \mathrm{C}$ and $E^{\prime} \approx 230 \mathrm{kPa}$ at $170{ }^{\circ} \mathrm{C}$, which corresponds to 20 and 10 network point(s) per $10^{4}$ carbons, respectively. We therefore estimate that the $\mathrm{PP}$ crystallites give rise to an equivalent of 10 physical network points per $10^{4}$ carbons at $140{ }^{\circ} \mathrm{C}$. Interestingly, the absolute modulus of the binary blend and XLPE is comparable, which indicates that the here proposed reactive compounding approach can result in a material with similar thermomechanical properties. For the ternary blend, we find $E^{\prime} \approx 87 \mathrm{kPa}$ at $140{ }^{\circ} \mathrm{C}$ and $E^{\prime} \approx 43 \mathrm{kPa}$ at $170{ }^{\circ} \mathrm{C}$, which corresponds to four and two network points per $10^{4}$ carbons, respectively. We therefore estimate that the PP crystallites give rise to an equivalent of two physical network points per $10^{4}$ carbons at $140{ }^{\circ} \mathrm{C}$.

Since our DMA measurements only allow studying elastic deformation, we also recorded the tensile strain at a constant stress of $1.6 \mathrm{kPa}$ during gradual heating (Figure $5 \mathrm{~b}$ ). While neat molten LDPE rapidly extends above $120^{\circ} \mathrm{C}$, in the case of the ternary blend, the strain initially remains low, reaching only $20 \%$ at $140{ }^{\circ} \mathrm{C}$. A more pronounced extension at higher temperatures coincides with the melting of the PP fraction with a peak $T_{\mathrm{m}}$ value $\approx 163{ }^{\circ} \mathrm{C}$. We conclude that the PP crystals are part of a continuous network that is able to resist the applied stress and therefore strengthens the molten LDPE. The PP fraction undergoes gradual melting, as evidenced by a broad DSC melting endotherm (Figure 5b), leading to a 

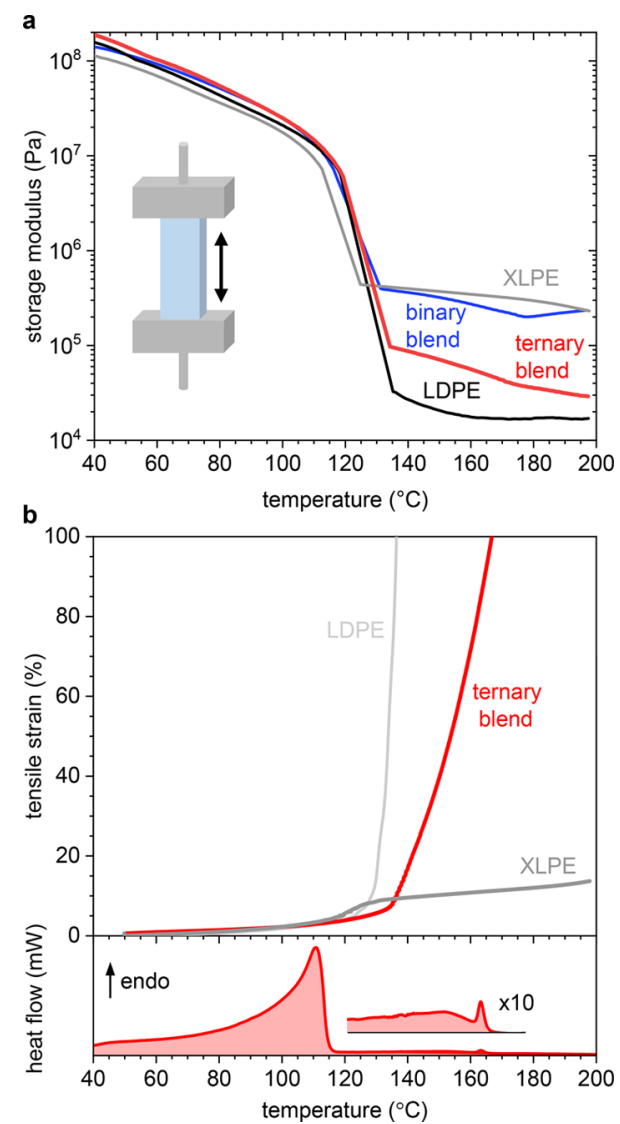

Figure 5. (a) Storage modulus measured with DMA as a function of temperature of the 4:1 $\mathrm{p}$ (E-stat-GMA):PP-graft-MA binary blend compounded at $170{ }^{\circ} \mathrm{C}$ for $5 \mathrm{~min}$ (blue) and the 24:6:70 $\mathrm{p}$ (E-statGMA):PP-graft-MA:LDPE ternary blend compounded at $170{ }^{\circ} \mathrm{C}$ for $10 \mathrm{~min}$ (red) as well as references LDPE (black) and XLPE, i.e., LDPE cross-linked with 1 wt $\%$ DCP at $200{ }^{\circ} \mathrm{C}$ (gray) (inset: schematic of the oscillatory DMA measurement indicating the direction of the applied stress). (b) Tensile strain at a constant stress of $1.6 \mathrm{kPa}$ during heating at $3{ }^{\circ} \mathrm{C} \mathrm{min}-1$ of the ternary blend compounded at $170{ }^{\circ} \mathrm{C}$ for $10 \mathrm{~min}$ (red), LDPE (light gray) and XLPE (gray) (top) and differential scanning calorimetry (DSC) first heating thermogram of the ternary blend (bottom).

gradual loss of the network, which explains why the strain response is more temperature-dependent than that of XLPE.

In a further set of experiments, we investigated to what extent the PP network is able to arrest creep of the ternary blend (cured for $10 \mathrm{~min}$ at $170{ }^{\circ} \mathrm{C}$ ) above the $T_{\mathrm{m}}$ of polyethylene. To quantify the creep behavior, we used a DMA instrument to monitor the creep strain at 120,130 , and $170{ }^{\circ} \mathrm{C}$ at a constant stress of $1 \mathrm{kPa}$, which approximately corresponds to the sample weight (Figure 6). At both 120 and $130{ }^{\circ} \mathrm{C}$, the strain first gradually increases and then reaches a close to constant value of not more than $30 \%$ at longer times. Instead, at $170{ }^{\circ} \mathrm{C}$, the material rapidly extends by more than $100 \%$, which again confirms that the internal network based on PP crystallites is critical for the observed thermoset-like behavior of the ternary blend. To confirm the importance of PP crystallites, we prepared a reference material where we replaced PP-graft-MA with maleic anhydride-grafted polyethylene (PEgraft-MA). Reassuringly, the cured 24:6:70 p(E-statGMA):PE-graft-MA:LDPE ternary blend undergoes rapid creep at $120{ }^{\circ} \mathrm{C}$, i.e., above the melting temperature of

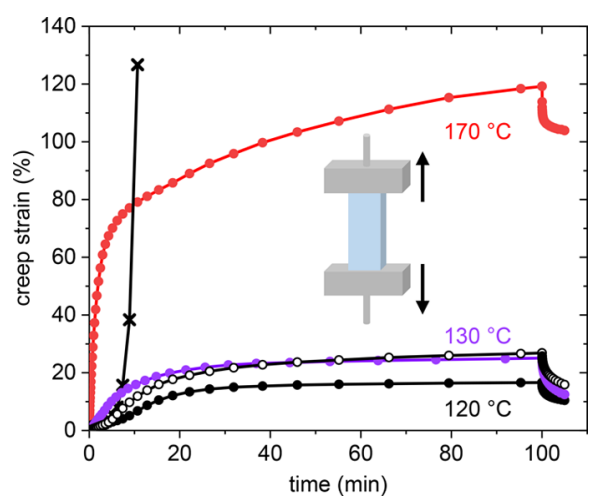

Figure 6. Creep strain at a constant stress of $1 \mathrm{kPa}$ (equivalent to the sample weight) at 120,130 , and $170{ }^{\circ} \mathrm{C}$ of the $24: 6: 70 \mathrm{p}$ (E-statGMA):PP-graft-MA:LDPE ternary blend compounded at $170{ }^{\circ} \mathrm{C}$ for $10 \mathrm{~min}$ (filled circles) and at $120{ }^{\circ} \mathrm{C}$ for the ternary blend after a second extrusion at $170{ }^{\circ} \mathrm{C}$ for $5 \mathrm{~min}$ (hollow circles) and also the 24:6:70 p(E-stat-GMA):PE-graft-MA:LDPE blend (crosses) (inset: schematic of the creep measurement indicating the direction of the applied stress).

polyethylene, because without the PP crystallites, insufficient cross-links are present to form a network (Figure 6).

Since recyclability is one of the advantages of thermoplastics, we investigated the creep performance of the ternary blend after a second extrusion step (Figure 6). We first carried out reactive compounding at $170{ }^{\circ} \mathrm{C}$ to prepare the cured ternary blend. Then, we cut the cured material into pieces and extruded a second time. We find that the re-extruded ternary blend continues to display a low degree of creep at $120{ }^{\circ} \mathrm{C}$, which suggests that the ternary blend maintains its excellent thermomechanical properties upon recycling.

A cable insulation material must, besides an adequate thermomechanical behavior, display excellent electrical insulation properties. We therefore measured the electrical DC conductivity $\sigma_{\mathrm{DC}}$ at $70{ }^{\circ} \mathrm{C}$ and $30 \mathrm{kV} \mathrm{mm}^{-1}$ by recording the leakage current of the material sandwiched between two electrodes (Figure 7) (cf. Experimental Section for details). After $18 \mathrm{~h}$ at $70{ }^{\circ} \mathrm{C}$, we extract a value of $\sigma_{\mathrm{DC}} \approx(2.5 \pm 0.3) \times$ $10^{-14} \mathrm{~S} \mathrm{~m}^{-1}$ for neat LDPE (Table 1). XLPE displays a slightly larger value of $\sigma_{\mathrm{DC}} \approx(4.0 \pm 0.4) \times 10^{-14} \mathrm{~S} \mathrm{~m}^{-1}$ (Figure S4), which we explain with the presence of residual cross-linking byproducts. Remarkably, despite the presence of unreacted

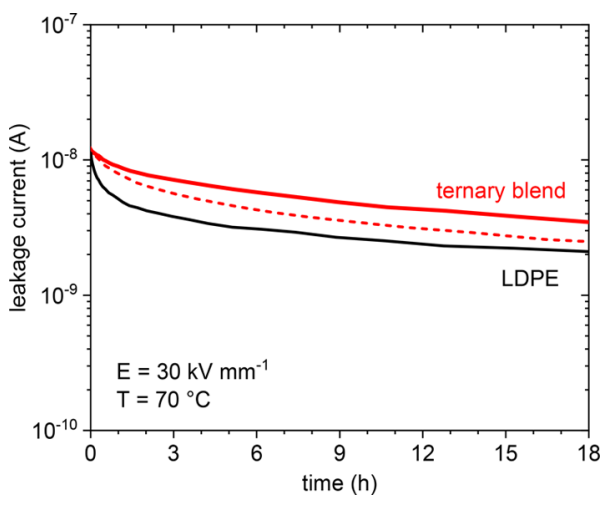

Figure 7. Leakage current as a function of time for the $24: 6: 70 \mathrm{p}(\mathrm{E}$ stat-GMA):PP-graft-MA:LDPE ternary blend after the first extrusion at $170{ }^{\circ} \mathrm{C}$ for $10 \mathrm{~min}$ (solid red line) and after the second extrusion at $170{ }^{\circ} \mathrm{C}$ for $5 \mathrm{~min}$ (dashed red line) and neat LDPE (solid black line). 
polar functional groups, the ternary blend features a similar DC electrical conductivity of $\sigma_{\mathrm{DC}} \approx(4.4 \pm 0.4) \times 10^{-14} \mathrm{~S} \mathrm{~m}^{-1}$. This suggests that the here explored formulations are indeed promising insulation materials. Importantly, the re-extruded ternary blend displays a similar $\sigma_{\mathrm{DC}} \approx(3.0 \pm 0.3) \times 10^{-14} \mathrm{~S}$ $\mathrm{m}^{-1}$, which indicates that the excellent electrical DC insulation properties are not affected by the recycling step.

\section{CONCLUSIONS}

We have shown that reactive compounding of a ternary blend comprising $\mathrm{p}$ (E-stat-GMA), PP-graft-MA, and up to $70 \mathrm{wt} \%$ LDPE allows the design of insulation materials with promising thermomechanical and electrical properties. Compounding at $170{ }^{\circ} \mathrm{C}$ triggers the byproduct-free reaction of epoxy and carboxyl groups, leading to the in situ formation of a PE-PPtype copolymer. The PE-PP copolymer shows good compatibility with LDPE, and the blends consisting of the PE-PP-type copolymer and LDPE display thermoset-like properties between the melting temperatures of polyethylene and polypropylene. We argue that the melt creep of the almost molten material is arrested through a continuous network held together by PP crystallites. Reprocessing at $170{ }^{\circ} \mathrm{C}$ can be carried out without compromising the excellent melt creep resistance and dielectric properties, which confirms that the here explored formulation is recyclable. Furthermore, we measured a very low $\mathrm{DC}$ electrical conductivity of $\sigma_{\mathrm{DC}} \approx 4.4 \times$ $10^{-14} \mathrm{~S} \mathrm{~m}^{-1}$ at $70{ }^{\circ} \mathrm{C}$ and $30 \mathrm{kV} \mathrm{mm}^{-1}$ for the ternary blend, which is on a par with values obtained for LDPE and XLPE. Evidently, the in situ formation of a PE-PP-type copolymer through reactive compounding is a promising approach that may enable the design of thermoplastic insulation materials.

\section{EXPERIMENTAL SECTION}

Materials. The $\mathrm{p}$ (E-stat-GMA) was obtained from Arkema (Lotader series AX8820, 4.5 wt \% GMA, melt flow index (MFI) = $2 \mathrm{~g} / 10 \mathrm{~min}\left(190{ }^{\circ} \mathrm{C} / 2.16 \mathrm{~kg}\right)$, density $\left.=0.93 \mathrm{~g} \mathrm{~cm}^{-3}\right)$. The isotactic polypropylene-maleic anhydride graft copolymer PP-graft-MA was obtained from Sigma-Aldrich (product no. 427845, 8-10 wt \% MA, density $=0.93 \mathrm{~g} \mathrm{~cm}^{-3}$, number-average molecular weight $\left(M_{\mathrm{n}}\right)=4 \mathrm{~kg}$ $\left.\mathrm{mol}^{-1}, \mathrm{PDI}=2.3\right)$. LDPE was obtained from Borealis AB (MFI $=2 \mathrm{~g} /$ $10 \mathrm{~min}\left(190{ }^{\circ} \mathrm{C} / 2.16 \mathrm{~kg}\right), M_{\mathrm{n}}=13 \mathrm{~kg} \mathrm{~mol}^{-1}$, PDI $=9$ and 1.9 longchain branches per 1000 carbons).

Compounding, Cross-Linking, and Sample Preparation. Reactive compounding of the binary and ternary blends was done by recirculation for $5-10 \mathrm{~min}$ at $170{ }^{\circ} \mathrm{C}$ in an Xplore Micro Compounder MC5 followed by extrusion. Samples for DSC, rheometry, DMA, and creep measurements were cut from 1.25 mm-thick plates and from $0.3 \mathrm{~mm}$ plates for DC conductivity measurements. These were prepared by heating the extruded material to $170{ }^{\circ} \mathrm{C}$ and melt-pressing it for $3 \mathrm{~min}$, or $1 \mathrm{~min}$ for rheometry samples, at a pressure of up to $3750 \mathrm{kPa}$ in a hot press before cooling. Reprocessing of the ternary blend was done by cutting these films into small fragments followed by compounding for $5 \mathrm{~min}$ at $170{ }^{\circ} \mathrm{C}$ and melt-pressing the extrudate in the same way. To prepare XLPE, milled LDPE was dispersed in a solution of DCP in methanol at $40{ }^{\circ} \mathrm{C}$ and stirred for $1 \mathrm{~h}$ followed by solvent evaporation. The resulting milled LDPE infused with $1 \mathrm{wt} \%$ DCP was melt-pressed at $120{ }^{\circ} \mathrm{C}$ for $5 \mathrm{~min}$ at a pressure of up to $3750 \mathrm{kPa}$ in a hot press. The temperature was then raised to $180^{\circ} \mathrm{C}$, where the sample was left to cross-link for 10 min before cooling. This XLPE sample was finally degassed in a vacuum oven at $50{ }^{\circ} \mathrm{C}$. Gel content measurements were done by submerging $150 \mathrm{mg}$ of material in $0.5 \mathrm{dm}^{3}$ decalin for $20 \mathrm{~h}$ followed by drying and weighing of the insoluble fraction. ${ }^{12}$

Transmission Fourier Transform Infrared (FTIR) Spectroscopy. Measurements were done in transmission with a PerkinElmer Frontier FTIR, fitted with a Linkam FTIR600 vertical stage, which was connected to a T95-LinkPad System Controller and LNP95 liquid nitrogen cooling pump. Each sample was prepared by dissolving the material in $p$-xylene and drop-casting on a calcium fluoride plate. After solvent evaporation, another calcium fluoride plate was placed on top of the drop-casted film before placing in the sample holder of the FTIR600 vertical stage.

Attenuated Total Reflectance (ATR) Fourier Transform Infrared (FTIR) Spectroscopy. Measurements were done with a PerkinElmer Frontier FTIR and a GladiATR accessory (Pike Technologies). Samples were prepared from films pressed for DMA measurements without further processing.

Differential Scanning Calorimetry (DSC). Measurements were done with a Mettler Toledo DSC2 (-50 to $200^{\circ} \mathrm{C}$, scan rate of $10^{\circ} \mathrm{C}$ $\mathrm{min}^{-1}, 5-10 \mathrm{mg}$ sample weight, $\mathrm{N}_{2}$ atmosphere).

Scanning Electron Microscopy (SEM). Surfaces were prepared by cryofracturing, etching ( $45 \mathrm{~min}$ with 1 wt $\% \mathrm{KMnO}_{4}$ in $\mathrm{H}_{2} \mathrm{SO}_{4}$, $\mathrm{H}_{3} \mathrm{PO}_{4}$, and $\left.\mathrm{H}_{2} \mathrm{O}\right)$, cleaning $\left(\mathrm{H}_{2} \mathrm{O}_{2}, \mathrm{H}_{2} \mathrm{O}\right.$, and $\left.\mathrm{CH}_{3} \mathrm{OH}\right)$, and finally $\mathrm{Pd}$ sputtering. Images were recorded with a LEO Ultra 55 SEM (3 kV acceleration voltage).

Dynamic Mechanical Analysis (DMA). Measurements were done with a TA Q800 DMA in tensile mode on $20 \times 5 \mathrm{~mm}$ pieces cut from $1.25 \mathrm{~mm}$-thick melt-pressed films. Variable-temperature measurements were done at a heating rate of $2{ }^{\circ} \mathrm{C} \min ^{-1}$ and a frequency of $0.5 \mathrm{~Hz}$. Tensile strain was recorded at a constant stress of $1.6 \mathrm{kPa}$ during heating at $3{ }^{\circ} \mathrm{C} \mathrm{min}^{-1}$. For creep measurements, samples were first heated from $25^{\circ} \mathrm{C}$ to a final temperature of 120 , 130 , or $170{ }^{\circ} \mathrm{C}$ at $10^{\circ} \mathrm{C} \mathrm{min}{ }^{-1}$ with a constant preload force of $1 \mathrm{mN}$ corresponding to a stress of $0.16 \mathrm{kPa}$. At the final temperature, the strain vs time was recorded at a constant stress of $1 \mathrm{kPa}$.

Rheometry. Oscillatory shear rheology was done with a DHR-3 (TA instruments) in parallel plate geometry (diameter $=25 \mathrm{~mm}$, gap $=1900 \mu \mathrm{m}$, normal force $=0.1 \mathrm{~N})$ at 130 and $170{ }^{\circ} \mathrm{C}(1 \mathrm{~Hz}$, maximum strain $=0.5 \%$ ).

DC Conductivity Measurements. Measurements were done in an oven with a setup comprising three electrodes (measuring area of $\varnothing=28 \mathrm{~mm}$ ). A DC voltage of $9 \mathrm{kV}$ was applied with a high-voltage power supply (Glassman FJ60R2) across $0.3 \mathrm{~mm}$-thick specimen films. The volume leakage current was logged with a Keithley 6517B electrometer followed by dynamic averaging. To filter out highfrequency noise, a low-pass filter was added to the circuit at the highvoltage side.

\section{ASSOCIATED CONTENT}

\section{Supporting Information}

The Supporting Information is available free of charge at https://pubs.acs.org/doi/10.1021/acsapm.0c00320.

FTIR spectra of PP-graft-MA, p(E-stat-GMA), and the binary blend, shear rheometry of ternary blend and $p(E$ stat-GMA), SEM images of LDPE-PP, binary, and ternary blends, DC conductivity measurements of LDPE, XLPE, and the ternary blend both before and after reprocessing (PDF)

\section{AUTHOR INFORMATION}

\section{Corresponding Author}

Christian Müller - Department of Chemistry and Chemical Engineering, Chalmers University of Technology, Göteborg 41296, Sweden; 이이.org/0000-0001-7859-7909;

Email: christian.muller@chalmers.se

\section{Authors}

Yingwei Ouyang - Department of Chemistry and Chemical Engineering, Chalmers University of Technology, Göteborg 41296, Sweden

Massimiliano Mauri - Department of Chemistry and Chemical Engineering, Chalmers University of Technology, Göteborg 41296, Sweden 
Amir Masoud Pourrahimi - Department of Chemistry and Chemical Engineering, Chalmers University of Technology, Göteborg 41296, Sweden; iorcid.org/0000-0001-5867-0531

Ida Östergren - Department of Chemistry and Chemical Engineering, Chalmers University of Technology, Göteborg 41296, Sweden

Anja Lund - Department of Chemistry and Chemical Engineering, Chalmers University of Technology, Göteborg 41296, Sweden

Thomas Gkourmpis - Innovation \& Technology, Borealis AB, Stenungsund 44486, Sweden; (1) orcid.org/0000-0001-78376823

Oscar Prieto - Innovation \& Technology, Borealis $A B$, Stenungsund 44486, Sweden

Xiangdong Xu - Department of Electrical Engineering, Chalmers University of Technology, Göteborg 41296, Sweden

Per-Ola Hagstrand - Innovation \& Technology, Borealis AB, Stenungsund 44486, Sweden

Complete contact information is available at:

https://pubs.acs.org/10.1021/acsapm.0c00320

\section{Notes}

The authors declare no competing financial interest.

\section{ACKNOWLEDGMENTS}

We gratefully acknowledge Borealis $\mathrm{AB}$ and the Swedish Foundation for Strategic Research (grant agreements FFL150147 and RMA15-0052) for funding, and the Chalmers Materials Analysis Laboratory (CMAL) for providing their LEO Ultra 55 SEM instrument.

\section{REFERENCES}

(1) Mazzanti, G.; Marzinotto, M. Extruded Cables for High-Voltage Direct-Current Transmission; Wiley: 2013.

(2) Montanari, G. C.; Morshuis, P. H. F.; Zhou, M.; Stevens, G. C.; Vaughan, A. S.; Han, Z.; Li, D. Criteria influencing the selection and design of $\mathrm{HV}$ and UHV DC cables in new network applications. High Voltage 2018, 3, 90.

(3) Andersson, M. G.; Hynynen, J.; Andersson, M. R.; Englund, V.; Hagstrand, P.-O.; Gkourmpis, T.; Müller, C. Highly Insulating Polyethylene Blends for High-Voltage Direct-Current Power Cables. ACS Macro Lett. 2017, 6, 78.

(4) Smedberg, A.; Hjertberg, T.; Gustafsson, B. Crosslinking reactions in an unsaturated Low density polyethylene. Polymer 1997, 38, 4127.

(5) Sahyoun, J.; Crepet, A.; Gouanve, F.; Keromnes, L.; Espuche, E. Diffusion mechanism of byproducts resulting from the peroxide crosslinking of polyethylene. J. Appl. Polym. Sci. 2017, 134, DOI: $10.1002 /$ app.44525.

(6) Andrews, T.; Hampton, R. N.; Smedberg, A.; Wald, D.; Waschk, V.; Weissenberg, W. The role of degassing in XLPE power cable manufacture. IEEE Electr. Insul. Mag. 2006, 22, 5.

(7) Fothergill, J. C.; Dodd, S. J.; Dissado, L. A.; Liu, T.; Nilsson, U. $\mathrm{H}$. The measurement of very low conductivity and dielectric loss in XLPE cables: A possible method to detect degradation due to thermal aging. IEEE Trans. Dielectr. Electr. Insul. 2011, 18, 1544.

(8) Englund, V.; Andersson, J.; Boström, J.-O.; Eriksson, V.; Hagstrand, P.-O.; Jungqvist, J.; Loyens, W.; Smedberg, A. Characteristics of Candidate Material Systems for Next Generation Extruded HVDC Cables. CIGRE Session: Paris, 2014; D1.104.

(9) Nilsson, U. H.; Andersson, J.; Englund, V.; Eriksson, V.; Hagstrand, P.-O.; Smedberg, A. The role and measurement of DC conductivity for HVDC cable insulation materials. In Annual Report Conference on Electrical Insulation and Dielectric Phenomena (CEIDP); IEEE: Ann Arbor, MI, 2015, pp 31.
(10) Mauri, M.; Tran, N.; Prieto, O.; Hjertberg, T.; Müller, C. Crosslinking of an ethylene-glycidyl methacrylate copolymer with amine click chemistry. Polymer 2017, 111, 27.

(11) Mauri, M.; Svenningsson, L.; Hjertberg, T.; Nordstierna, L.; Prieto, O.; Müller, C. Orange is the new white: rapid curing of an ethylene-glycidyl methacrylate copolymer with a Ti-bisphenolate type catalyst. Polym. Chem. 2018, 9, 1710.

(12) Mauri, M.; Peterson, A.; Senol, A.; Elamin, K.; Gitsas, A.; Hjertberg, T.; Matic, A.; Gkourmpis, T.; Prieto, O.; Müller, C. Byproduct-free curing of a highly insulating polyethylene copolymer blend: an alternative to peroxide crosslinking. J. Mater. Chem. C 2018, 6, 11292 .

(13) Mauri, M.; Hofmann, A. I.; Gómez-Heincke, D.; Kumara, S.; Pourrahimi, A. M.; Ouyang, Y.; Hagstrand, P.-O.; Gkourmpis, T.; Xu, X.; Prieto, O.; Müller, C. Click chemistry-type crosslinking of a lowconductivity polyethylene copolymer ternary blend for power cable insulation. Polym. Int. 2020, 69, 404.

(14) Tellers, J.; Canossa, S.; Pinalli, R.; Soliman, M.; Vachon, J.; Dalcanale, E. Dynamic Cross-Linking of Polyethylene via Sextuple Hydrogen Bonding Array. Macromolecules 2018, 51, 7680.

(15) Zych, A.; Verdelli, A.; Soliman, M.; Pinalli, R.; Vachon, J.; Dalcanale, E. Physically cross-linked polyethylene via reactive extrusion. Polym. Chem. 2019, 10, 1741.

(16) Andersson, M. G.; Hynynen, J.; Andersson, M. R.; Hagstrand, P.-O.; Gkourmpis, T.; Müller, C. Additive-like amounts of HDPE prevent creep of molten LDPE: Phase-behavior and thermomechanical properties of a melt-miscible blend. J. Polym. Sci., Part B: Polym. Phys. 2017, 55, 146.

(17) Andersson, M. G.; Städler, R.; Hagstrand, P.-O.; Gkourmpis, T.; Andersson, M. R.; Müller, C. Influence of Molecular Weight on the Creep Resistance of Almost Molten Polyethylene Blends. Macromol. Chem. Phys. 2018, 219, 1700072.

(18) Green, C. D.; Vaughan, A. S.; Stevens, G. C.; Sutton, S. J.; Geussens, T.; Fairhurst, M. J. Recyclable power cable comprising a blend of slow-crystallised polyethylenes. IEEE Trans. Dielectr. Electr. Insul. 2013, 20, 1.

(19) Dang, B.; He, J.; Hu, J.; Zhou, Y. Large improvement in trap level and space charge distribution of polypropylene by enhancing the crystalline-amorphous interface effect in blends. Polym. Int. 2016, 65, 371.

(20) Green, C. D.; Vaughan, A. S.; Stevens, G. C.; Pye, A.; Sutton, S. J.; Geussens, T.; Fairhurst, M. J. Thermoplastic Cable Insulation Comprising a Blend of Isotactic Polypropylene and a Propyleneethylene Copolymer. IEEE Trans. Dielectr. Electr. Insul. 2015, 22, 639.

(21) He, J.; Zhou, Y. Progress in Eco-friendly High Voltage Cable Insulation Material. In 2018 12th International Conference on the Properties and Applications of Dielectric Materials (ICPADM); IEEE: 2018, 11.

(22) Hosier, I. L.; Vaughan, A. S.; Swingler, S. G. An investigation of the potential of polypropylene and its blends for use in recyclable high voltage cable insulation systems. J. Mater. Sci. 2011, 46, 4058.

(23) Zhou, Y.; He, J.; Hu, J.; Huang, X.; Jiang, P. Evaluation of Polypropylene/Polyolefin Elastomer Blends for Potential Recyclable HVDC Cable Insulation Applications. IEEE Trans. Dielectr. Electr. Insul. 2015, 22, 673.

(24) Belli, S.; Perego, G.; Bareggi, A.; Caimi, L.; Donazzi, F.; Zaccone, E., P-Laser Breakthrough in power cable systems. In 2010 IEEE International Symposium on Electrical Insulation; IEEE: San Diego, CA, 2010, DOI: 10.1109/ELINSL.2010.5549826pp 1.

(25) Torres, N.; Robin, J. J.; Boutevin, B. Study of Compatibilization of HDPE-PET Blends by Adding Grafted or Statistical Copolymers. J. Appl. Polym. Sci. 2001, 81, 2377.

(26) Wei, Q.; Chionna, D.; Galoppini, E.; Pracella, M. Functionalization of LDPE by Melt Grafting with Glycidyl Methacrylate and Reactive Blending with Polyamide-6. Macromol. Chem. Phys. 2003, 204, 1123.

(27) Chiono, V.; Filippi, S.; Yordanov, H.; Minkova, L.; Magagnini, P. Reactive compatibilizer precursors for LDPE/PA6 blends. III: ethylene-glycidylmethacrylate copolymer. Polymer 2003, 44, 2423. 
(28) Xu, Y.; Loi, J.; Delgado, P.; Topolkaraev, V.; McEneany, R. J.; Macosko, C. W.; Hillmyer, M. A. Reactive Compatibilization of Polylactide/Polypropylene Blends. Ind. Eng. Chem. Res. 2015, 54, 6108.

(29) Briceño Garcia, R. D.; Keromnes, L.; Goutille, Y.; Cassagnau, P.; Fenouillot, F.; Chaumont, P. Structural evolution of a constrained epoxy functional polyethylene network crosslinked by a bio-based reactant. Eur. Polym. J. 2014, 61, 186.

(30) Lu, J. Z.; Wu, Q.; McNabb, H. S. Chemical coupling in wood fiber and polymer composites: a review of coupling agents and treatments. Wood Fiber Sci. 2000, 32, 88.

(31) Yin, S.; Tuladhar, R.; Shi, F.; Shanks, R. A.; Combe, M.; Collister, T. Mechanical reprocessing of polyolefin waste: A review. Polym. Eng. Sci. 2015, 55, 2899.

(32) Zha, J.-W.; Wu, Y.-H.; Wang, S.-J.; Wu, D.-H.; Yan, H.-D.; Dang, Z.-M. Improvement of Space Charge Suppression of Polypropylene for Potential Application in HVDC Cables. IEEE Trans. Dielectr. Electr. Insul. 2016, 23, 2337.

(33) Sclavons, M.; Franquinet, P.; Carlier, V.; Verfaillie, G.; Fallais, I.; Legras, R.; Laurent, M.; Thyrion, F. C. Quantification of the maleic anhydride grafted onto polypropylene by chemical and viscosimetric titrations, and FTIR spectroscopy. Polymer 2000, 41, 1989. 